\title{
Afastamento do trabalho e funcionalidade: o caso de trabalhadores adoecidos por doenças da coluna lombar
}

\author{
Maria do Carmo Baracho de Alencar ${ }^{a}$, Janaina Bussola Montrezor Valença ${ }^{b}$ \\ aDepartamento de Gestão e Cuidados em Saúde, Universidade Federal de São Paulo - UNIFESP/BS, \\ Santos, SP, Brasil. \\ bUniversidade Federal de São Paulo - UNIFESP/BS, Santos, SP, Brasil.
}

\begin{abstract}
Resumo: Objetivo: Investigar os aspectos funcionais de sujeitos acometidos por doenças crônicas da coluna lombar e em situação de afastamento do trabalho. Método: Duas etapas. (1) Análise documental de prontuários abertos de pacientes atendidos no Centro de Referência em Saúde do Trabalhador (CEREST), Santos-SP, seleção de sujeitos com diagnóstico clínico de "outras dorsopatias" e queixa inicial de dor lombar. (2) Utilização de roteiro com questões semiestruturadas para a realização de entrevistas junto aos sujeitos, que foram gravadas e transcritas para análise de conteúdo, e também aplicação do instrumental Oswestry Low back Pain Scale-OSW. Resultados: Foram analisados 431 prontuários de pacientes de ambos os gêneros e 15,77\% (68) apresentaram diagnóstico de "outras dorsopatias"; destes, 73,5\% (50) apresentaram queixa inicial de lombalgia. Participaram das entrevistas dez (10) sujeitos, de faixa etária entre 35 a 58 anos de idade, de ambos os gêneros, profissões variadas, apresentando-se, a maioria, com baixa escolaridade. Entre os sujeitos, foram encontradas as seguintes condições: a perda de identidade em papéis sociais, em função da incapacidade; posturas que desencadeiam dores no cotidiano de vida; a necessidade de executar tarefas que podem desencadear dores, e sofrimento mental diante das situações, entre outros. Conclusão: O afastamento do trabalho por lombalgia crônica pode causar incapacidades e sofrimento, e os aspectos funcionais são relacionais e devem ser analisados e tratados sob a perspectiva biopsicossocial e por equipes multiprofissionais.
\end{abstract}

Palavras-chave: Licença Médica, Dor Lombar, Dor Crônica, Saúde do Trabalhador.

\section{Absence from work and functionality: the case of workers with lower back diseases}

\begin{abstract}
Objective: To investigate the functional aspects of subjects affected by chronic diseases involving the lumbar spine and in absence from work. Method: Two steps. (1) Documentary analysis of open records of patients treated at the Worker's Health Reference Center (CEREST), Santos-SP, selection of subjects with a clinical diagnosis of "other back diseases" and initial complaint of lower back pain. (2) Use the script with semi-structured questions for the interviews with the subjects, which were recorded and transcribed for content analysis, and also an application of the Oswestry Low Back Pain Scale-OSW tool. Results: We analyzed 431 records with patients of both genders, and $15.77 \%$ (68) were diagnosed with "other back diseases". Of these, 73.5\% (50) presented initial complaint of lower back pain. Ten (10) subjects participated of the interview, aged between 35-58 years, both genders, different professions, and most with little schooling. Among the subjects were found the loss of identity in social roles based on disability, postures that can trigger pain in everyday life, the need to perform tasks that can trigger pain, mental suffering related to situations, among others. Conclusion: The leave of absence due to chronic lower back pain may cause disability and suffering, and functional aspects are relational and must be analyzed and dealt with the biopsychosocial perspective and multidisciplinary teams.
\end{abstract}

Keywords: Sick Leave, Low Back Pain, Chronic Pain, Occupational Health.

Autor para correspondência: Maria do Carmo Baracho de Alencar, Universidade Federal de São Paulo, Rua Silva Jardim, 136, Vila Mathias, CEP 11015-020, Santos, SP, Brasil, e-mail: alencar@unifesp.br

Recebido em Set. 16, 2015; $1^{\text {a }}$ Revisão em Fev. 18, 2016; 2a Revisão em Mar. 16, 2016; Aceito em Abr. $23,2016$. 


\section{Introdução}

Diversas mudanças ocorreram no mundo do trabalho nas últimas décadas e estas vêm afetando a saúde dos trabalhadores de diversas formas. Os contextos atuais de trabalho, com condições precárias, instabilidade de emprego, pouca possibilidade de desenvolvimento e crescimento profissional, bem como modos agressivos de organização do trabalho, que exigem metas difíceis de serem alcançadas e que causam um mal-estar junto aos trabalhadores, podem contribuir para o adoecimento do trabalhador. Há necessidade de se ter prazer no trabalho e de se evitar o sofrimento. O prazer é parte constituinte da saúde, é um ato criativo diante da própria vida, além de dar um significado ao viver (MENDES; CRUZ, 2004). Segundo os autores, o prazer no trabalho está relacionado à identidade social e pessoal. Esta identidade se desvela porque o trabalho é visto como um aspecto central e importante para a socialização humana. Segundo Lancman (2008), o desenvolvimento da identidade e a transformaçáo do sofrimento em prazer estâo diretamente relacionados ao olhar do outro e aos mecanismos de reconhecimento decorrentes deste olhar.

A experiência de afastamento do trabalho por adoecimento profissional está marcada social e historicamente pela incapacidade para o trabalho e pela insegurança (RAMOS; TITTONI; NARDI, 2008). Por incapacidade, entende-se o(s) impacto(s) que as condiçóes agudas e crônicas têm nas funçôes corporais e na habilidade de o indivíduo atuar de modo esperado e pessoalmente desejável na sociedade (ORGANIZAÇÃO..., 2003). A discriminação e a rejeição, para o mundo do trabalho, geram o atestado público de declínio profissional, o descrédito quanto à condição de doente e o desengano quanto à possibilidade de melhora (NEVES; NUNES, 2009).

Entre as doenças do trabalho, estão as doenças da coluna vertebral. Dentre as doenças da coluna vertebral, encontram-se as cervicalgias, as dores torácicas e ciáticas, os transtornos dos discos intervertebrais, as espondiloses, as radiculopatias e dorsalgias, que são as mais comuns (HAGEN et al., 2002). Uma das regiôes corporais mais acometidas é a regiáo lombar. Segundo Helfenstein, Goldenfum e Siena (2010), a lombalgia ocupacional é a maior causa isolada de transtorno de saúde relacionado com o trabalho e absenteísmo, sendo também a causa mais comum de incapacidade em trabalhadores com menos de 45 anos de idade.

Fatores relacionados à atividade profissional, como profissôes com grande sobrecarga física, postura inadequada, movimentos repetitivos, sujeição à vibração e trabalhos em grande velocidade são de risco para lombalgias (ABREU; RIBEIRO, 2010). Aspectos relativos à organização do trabalho, como altas exigências por produtividade, ritmo acelerado, longas jornadas e condiçôes inadequadas de trabalho também são relacionados às doenças (ALENCAR; TERADA, 2012). As dores lombares são um problema de saúde pública em vários países (HOY et al., 2012; GOLOB; WIPF, 2014). Inicialmente, os sintomas são agudos, mas, ao longo de meses, podem se tornar crônicos.

Para Zavarize et al. (2014), a dor lombar crônica constitui a principal causa de absenteísmo no trabalho, é causa de incapacidade nos indivíduos na faixa etária produtiva e é uma das causas mais onerosas de afecçôes do aparelho locomotor. Na lombalgia crônica, é comum ocorrer limitaçóes funcionais nas atividades de vida diária e de vida prática, além de restrição na participação do indivíduo na sociedade (lazer, trabalho, escola) (SAMPAIO et al., 2005). Em virtude da dor, grande parte dos pacientes se torna parcial ou totalmente incapacitado, transitória ou permanentemente, desencadeando acentuado sofrimento e perda na qualidade de vida (GARCIA; TORRES NETO, 2011).

$\mathrm{Na}$ lombalgia crônica, a incapacidade funcional faz com que os doentes sintam dificuldades de realizar as atividades, tendo, muitas vezes, que se movimentar de modo lento e cuidadoso, o que faz com que queiram ficar em casa na maior parte do tempo (WEINER et al., 2006). Esta incapacidade pode conduzir os sujeitos acometidos a um maior isolamento social. Incapacidade e declínio da funcionalidade são comuns entre pacientes com dor lombar crônica, sendo que a qualidade de vida dos pacientes depende mais do grau de incapacidade do que da intensidade da dor; ou seja, a maioria dos custos deriva da incapacidade e náo da dor (SALVETTI, 2010).

A Organização Mundial de Saúde (OMS) aprovou, em 2001, o sistema de classificação definitivo para o entendimento da funcionalidade e da incapacidade humana: a Classificaçáo Internacional de Funcionalidade, Incapacidade e Saúde - CIF (ORGANIZAÇÃO..., 2003). A CIF descreve a funcionalidade e a incapacidade relacionadas às condiçôes de saúde, identificando o que uma pessoa "pode ou não pode fazer na sua vida diária", tendo em vista as funçôes dos órgãos ou sistemas e estruturas do corpo, assim como as limitaçôes de atividades e da participação social no meio ambiente no qual a pessoa vive (BATTISTELLA; BRITO, 2002). O termo do modelo da CIF é a funcionalidade, que cobre os componentes de funçôes e estruturas do corpo, 
atividade e participação social, em que a funcionalidade é usada no aspecto positivo e o aspecto negativo corresponde à incapacidade (ORGANIZAÇÃO..., 2003). O objetivo da classificação é agrupar aspectos semelhantes da funcionalidade humana, organizá-los em uma estrutura lógica e defini-los de forma que os termos usados nesta classificação sejam equivalentes no âmbito internacional (RIBEIRO, 2011).

A OMS destaca a importância da abordagem biopsicossocial para integrar várias perspectivas $\mathrm{da}$ funcionalidade humana, mas não detalha como se dá essa interação (SAMPAIO; LUZ, 2009). Segundo esses autores, a interação é complexa, e uma abordagem biopsicossocial é usada para se obter a integração das várias dimensões da saúde - biológica, individual e social. O desafio posto é entender a relação complexa entre fatores biológicos e psicossociais, refinando a análise da relação entre deficiência e incapacidade, a partir da percepçáo do corpo como fenômeno biológico e produção social.

A sociedade impóe normas e regras para o que seria considerado "normal", junto aos sujeitos adoecidos, e dentro de uma análise funcional. E há de se considerar o que seria normal, pois, segundo Canguilhem (2014), o normal não é um conceito estático ou pacífico, e sim dinâmico e polêmico. O normal depende de regras e normas; então, poderia ser considerado "normal" um sujeito adoecido com dores osteomusculares não ter atividades sociais, para determinada sociedade, e, portanto, sua funcionalidade poderia estar comprometida por aspectos socioculturais, afetando a sua participação social. Talvez este fato possa ocorrer não pelo acometimento da doença em si, mas por receios gerados pelas possíveis representaçóes da doença e da situação. Ainda, o quanto o sujeito estaria ou náo também motivado para se tornar ou não capaz de executar determinado movimento ou tarefa, e sob quais condiçôes, e quais seriam as necessidades, expectativas e implicaçóes envolvidas? Relevando a complexidade das interaçôes existentes, inclusive no âmbito individual. Duas pessoas com a mesma doença podem ter diferentes níveis de funcionalidade, e duas pessoas com o mesmo nível de funcionalidade não têm necessariamente a mesma condição de saúde (FARIAS; BUCHALLA, 2005).

As dores relacionadas à coluna lombar interferem nas atividades de vida diária, gerando desde limitaçóes de movimentos simples, como permanecer em pé ou sentado, andar, em cuidados pessoais e atividade sexual, até invalidez em casos mais severos (SALATE; SUEISHI, 2011). O impacto da lombalgia na funcionalidade é consenso entre os profissionais de saúde, podendo restringir principalmente as atividades ocupacionais, gerando repercussóes socioeconômicas importantes (SAMPAIO et al., 2005). A necessidade de se conhecer o que acontece com os pacientes após diagnóstico e ao longo do tempo, principalmente em relação às doenças crônicas, torna-se cada vez mais importante para a área da saúde (FARIAS; BUCHALLA, 2005).

Este estudo objetivou investigar aspectos funcionais de sujeitos acometidos por doenças crônicas da coluna lombar e em situação de afastamento do trabalho.

\section{Método}

Este estudo é exploratório, descritivo e retrospectivo, com ênfase em resultados qualitativos, tendo sido realizado em duas etapas. Na primeira etapa, foi realizada análise documental de prontuários abertos de sujeitos atendidos no Centro de Referência em Saúde do Trabalhador, CEREST, da cidade de Santos-SP, no período de janeiro de 2010 a dezembro de 2011. Ocorreu o levantamento dos dados pessoais, de profissão, diagnóstico clínico, causa do afastamento, tempo de afastamento, entre outros. O critério de inclusão nesta etapa foi de sujeitos que apresentaram diagnóstico clínico referente a "outras Dorsopatias" (entre M50 a M54), estabelecido de acordo com a Classificação Internacional de Doenças (CID-10). $\mathrm{Na}$ segunda etapa, a partir dos prontuários já selecionados na etapa anterior, foram selecionados esses sujeitos, de ambos os gêneros, que vivenciaram ou que estavam em situação de afastamento do trabalho devido às dorsopatias e com queixa registrada, em consulta inicial, de lombalgia.

Foi realizado contato telefônico com todos os sujeitos selecionados para a segunda etapa e feito o agendamento junto aos que concordaram em participar do estudo. Alguns contatos não foram possíveis devido à mudança de número telefônico. Um roteiro foi elaborado para as entrevistas semiestruturadas, contendo questóes sobre as dificuldades atuais vivenciadas no cotidiano de vida em diversos âmbitos da vida (familiar, lazer, de trabalho, etc), a partir de vivências e percepçóes do sujeito. $\mathrm{O}$ entrevistador formulou as questóes que julgou necessárias visando a esclarecer assuntos que não estavam claros e/ou obter as informaçôes que considerou relevantes ao estudo, com base no roteiro elaborado para as entrevistas. Esta etapa foi gravada e as entrevistas tiveram uma duraçáo média de 60 minutos. As entrevistas foram gravadas e transcritas na íntegra para análise de conteúdo por categorias temáticas (BARDIN, 2011). Segundo a autora, as categorias são classes, as quais reúnem um grupo de elementos (unidades de registro) sob um 
título genérico, e cujo agrupamento é efetuado em razão de características comuns destes elementos. Neste estudo, optou-se, em algumas categorias, por títulos em elementos agrupados.

Como complemento, foi também aplicado o instrumento Oswestry Low Back Pain Disability Questionnaire - OWS (FAIRBANK; PYNSENT, 2000). Este questionário consiste em dez itens que se referem aos aspectos funcionais e estáo relacionados ao quanto o problema nas costas tem afetado o dia a dia, com itens sobre: cuidados pessoais, capacidade de levantar pesos, de andar, entre outros. Cada item tem um escore de 0 a 5 , sendo que os escores mais altos indicam grande incapacidade. Se todos os dez itens forem completados, a pontuação é calculada da seguinte forma: se a pontuação final foi 16 (soma dos pontos obtidos), sendo 50 os pontos possíveis, $16 / 50 \times 100=32 \%$. Os autores recomendam arredondar as porcentagens para o número inteiro. Para as análises desse instrumental: 0 a 20\% - mínima incapacidade; $21 \%$ a $40 \%$ - moderada incapacidade; $41 \%$ a $60 \%$ - severa incapacidade; $61 \%$ a $80 \%$ fisicamente incapacitado; $81 \%$ a $100 \%$ - totalmente incapacitado (geralmente, acamados).

O estudo foi aprovado pelo Comitê de Ética em Pesquisa, da Universidade Federal de São Paulo - UNIFESP, sob o número 186.843.

\section{Resultados e Discussão}

Foram analisados 431 prontuários de sujeitos que foram atendidos no Centro de Referência em Saúde do Trabalhador (CEREST), na cidade de Santos-SP,

Tabela 1. Dados pessoais, de profissão e tempo de afastamento dos sujeitos entrevistados com doenças da coluna lombar.

\begin{tabular}{|c|c|}
\hline Dados & $\mathrm{N}=10$ \\
\hline Faixa etária & De 35 a 58 anos de idade \\
\hline Gênero & $\begin{array}{l}\text { Feminino: } \mathrm{n}=6 \\
\text { Masculino: } \mathrm{n}=4\end{array}$ \\
\hline Estado civil & $\begin{array}{l}\text { Casado: } \mathrm{n}=8 \\
\text { Divorciado: } \mathrm{n}=1 \\
\text { Viúvo: } \mathrm{n}=1\end{array}$ \\
\hline Escolaridade & $\begin{array}{l}\text { Ensino Médio incompleto: } \mathrm{n}=6 \\
\text { Ensino Médio completo: } \mathrm{n}=4\end{array}$ \\
\hline Profissão & $\begin{array}{l}\text { Auxiliar de limpeza: } \mathrm{n}=3 \\
\text { Auxiliar de serviços gerais: } \mathrm{n}=3 \\
\text { Auxiliar de enfermagem: } \mathrm{n}=1 \\
\text { Pizzaiolo: } \mathrm{n}=1 \\
\text { Fiscal de carga e descarga: } \mathrm{n}=1 \\
\text { Pedreiro: } \mathrm{n}=1\end{array}$ \\
\hline $\begin{array}{l}\text { Tempo total de } \\
\text { afastamento do } \\
\text { trabalho }\end{array}$ & $\begin{array}{l}\text { Superior a } 3 \text { anos: } \mathrm{n}=6 \\
\text { Inferior a } 3 \text { anos: } \mathrm{n}=4\end{array}$ \\
\hline
\end{tabular}

no período de janeiro de 2010 a dezembro de 2011 . Desses prontuários, 15,7\% ( $\mathrm{n}=68)$ trabalhadores apresentavam diagnósticos clínicos estabelecidos entre M50 a M54, pela CID-10. Dessa amostra, $52,9 \%$ dos sujeitos eram do gênero masculino, sendo a faixa etária mais acometida entre 41 e 50 anos. Entre os diagnósticos clínicos mais prevalentes nesta amostra, estavam: outros transtornos de discos intervertebrais (M51); lumbago com ciática (M54.4); transtornos de discos lombares e de outros discos intervertebrais com radiculopatia (M51.1), e Dorsalgia (M54). As dorsopatias envolvem várias regiôes da coluna vertebral e a queixa de lombalgia, entre os trabalhadores em consulta inicial, foi de 73,5\% $(\mathrm{n}=50)$. Destes, alguns sujeitos apresentavam sintomas de lombociatalgia, além de lombalgia decorrente de diagnósticos clínicos relacionados aos transtornos dos discos intervertebrais lombares. A Hérnia Discal Lombar é um problema que atinge grande parte da população e, além de causar desconforto, gera também uma série de inconveniências na vida profissional e psicossocial do indivíduo acometido, em diferentes faixas etárias e sociais (FRITZ et al., 2010).

Foi estabelecido contato com os 50 sujeitos com dorsopatias em regiāo lombar (73,5\% dos 68), para a realização das entrevistas. Participaram, da segunda etapa do estudo, dez sujeitos. Os dados pessoais, de profissão e tempo de afastamento dos entrevistados estão demonstrados na Tabela 1 .

Conforme demonstrado na Tabela 1, a idade variou entre 35 e 58 anos de idade, sendo que, destes, seis sujeitos tinham idade inferior a 45 anos. Para alguns autores, há um acometimento maior em faixas etárias a partir de 40 anos e em idade produtiva (HEDEAGER-MOMSEN et al., 2014; HELFENSTEIN; GOLDENFUM; SIENA, 2010). Entre as profissóes, houve uma prevalência, nesta amostra $(n=6)$, de auxiliares de limpeza e de serviços gerais. Esses trabalhadores, de acordo com Pataro e Fernandes (2014), exercem profissóes expostas a riscos ocupacionais, especialmente com alta sobrecarga física de trabalho, com riscos de dores lombares e, consequentemente, ocorre o afastamento do trabalho. O tempo de afastamento da maioria dos sujeitos $(n=6)$ foi superior a três anos e a maioria havia vivenciado o retorno ao trabalho $(n=6)$. O tempo prolongado em situaçáo de afastamento do trabalho pode ser um fator negativo para o retorno ao trabalho (STAAL et al., 2003; TOLDRÁ et al., 2010). A maioria apresentou uma baixa escolaridade, com Ensino Médio incompleto, e todos referiram esforços físicos em atividades de trabalho.

Todos os sujeitos $(n=10)$ eram acometidos em região da coluna lombar com protusão discal lombar 
e nenhum deles havia realizado cirurgia, apenas tratamentos, como medicamentosos e fisioterápicos, em alguns momentos do período total de afastamento. Todos os sujeitos $(\mathrm{n}=10)$ se encontravam em situaçáo de afastamento do trabalho no momento da pesquisa e recebiam o benefício previdenciário auxílio-doença (B31). A maioria $(\mathrm{n}=6)$ tinha vivenciado mais de um processo de afastamento do trabalho, o que indica terem vivenciado situaçóes que podem ser boas ou ruins, e que podem repercutir em suas vidas, incluindo possíveis relações e condiçóes insatisfatórias no processo de retorno ao trabalho, que não foram investigadas.

\subsection{Identidade, incapacidade e sofrimento}

Todos os sujeitos apresentaram sintomas dolorosos crônicos, que afetavam as atividades práticas e instrumentais de vida diária. Essas atividades afetam papéis sociais, como o de trabalhador, de dona de casa, entre outros, o que gerava sofrimento. Os sujeitos buscavam por auxílio de familiares, quando possível, em atividades domésticas, mas, ao mesmo tempo, se gerava um sentimento de incapacidade e dependência de outros para a realização de algumas tarefas.

[...] porque hoje, nem o serviço de casa eu consigo fazer, o serviço "normal" eu não consigo fazer, já fico 'descadeirada' ... até para estender uma roupa! Tenho que depender dos filhos ou do marido (43 anos, auxiliar de serviços gerais, gênero feminino).

[...] na minha casa meus filhos têm que fazer as coisas para mim porque eu náo consigo... ele (marido) que faz para mim porque eu náo consigo... e saber que um dia eu já fiz isso e muito mais, é horrivel... ter que depender dos outros para fazer suas coisas (44 anos, auxiliar de enfermagem, gênero feminino).

Ter que depender de outros para realizar tarefas antes facilmente realizáveis pareceu "atestar" uma condição de incapacidade e inutilidade, pelos significados atribuídos. Nem sempre é possível ter alguém em casa disponível quando se precisa para ajudar nas tarefas e também pode ser sofrido ter de deixar o outro realizá-las por você, quando há um desejo em realizá-las. Essas vivências podem reforçar a identidade de doente e incapaz, gerando sofrimento. A incapacidade física e emocional tende a suspender as atividades de vida diária, de dona de casa e esposa, e as mulheres acabam por manifestarem quadros depressivos (GAEDKE; KRUG, 2008). Os sujeitos podem necessitar de adaptaçóes e apoio familiar no processo, especialmente quando as relaçóes interpessoais familiares acontecem em padrôes considerados disfuncionais, aspecto que necessitaria de maiores investigaçóes. Segundo Rocha e Lima (2011), o trabalhador doente, incapacitado e afastado, procura abrigo no ambiente da família, e há exigências de esforços da família em lidar com as novas demandas que surgem após o adoecimento.

Tanto os homens quanto as mulheres deste estudo sofreram pela incapacidade para o trabalho, deixando de lado a identidade de trabalhador capacitado e "eficiente", e valorizado socialmente.

[...] a gente se sente um lixo porque enquanto a gente está trabalhando somos trabalhadores, somos pessoas boas... depois a gente tem, adquire um problema, ai tratam a gente como se fosse um ninguém... infelizmente é isso que acontece (37 anos, auxiliar de serviços gerais, gênero masculino).

[...] a gente se sente incapaz, né? Um coitado... porque poxa vida, eu não consigo fazer as coisas que eu fazia tão bem (55 anos, pedreiro, gênero masculino).

As percepçóes e ideias de incapacidade se fortalecem pelo meio social. Para Canguilhem (2014), estar doente significa ser nocivo, indesejável ou socialmente desvalorizado. Nesse sentido, pelas regras e normas sociais convencionais, busca-se uma cura, porém doenças crônicas náo têm cura. Talvez deva-se ter mais cuidado ao informar sobre o diagnóstico de uma doença crônica, pois a informação carrega estigmas e o diagnóstico pode vir como uma verdade absoluta. Quando uma doença se torna crônica, há sempre um "passado", e a pessoa é doente náo somente em relação a si, mas também em relação aos outros (CANGUILHEM, 2014). Não está claro como a normalidade pode ser definida quando se trata de estruturas, funçóes, atividades e desempenho de papéis que "normalmente" apresentam grande variabilidade (SAMPAIO; LUZ, 2009).

A atenção à saúde dos trabalhadores incapazes para o trabalho precisa ser revista por meio de uma lente mais ampliada, uma perspectiva holística de cuidado (NEVES; NUNES, 2009). Deve-se levar em conta o sofrimento, as condiçóes de vida, as expectativas, as crenças, e que as experiências e vivências dos sujeitos, seus modos de ser e reagir, sofrem influências da sociedade a qual pertencem.

\subsection{Posturas e dores}

Posturas comuns no cotidiano de vida, como ficar sentada ou permanecer de pé por algum tempo, foram comprometidas pela doença em algumas situaçóes. 
[...] se eu ficar muito de pé parada, não consigo muito não, só se for uns 10 minutos... se não já começa a doer... então eu tenho que ficar me movimentando para lá e para cá... entendeu? (53 anos, auxiliar de limpeza, gênero feminino).

[...] às vezes a gente não pode ficar muito tempo em pé e nem muito tempo sentado, então qual o trabalho que a gente vai encontrar nesta forma? (37 anos, auxiliar de serviços gerais, gênero masculino).

Questôes simples, como ficar sentada ou em pé por algum tempo, frequentemente ocasionavam dores e, por serem posturas comuns do cotidiano, acabavam por gerar sofrimento pela incapacidade percebida. $\mathrm{O}$ fato de a dor surgir em determinados posicionamentos, sem necessariamente haver esforço físico, exceto o próprio esforço de manutenção corporal, pode acentuar o medo da dor e a crença de incapacidade. Níveis de fobia relacionados às situaçôes dolorosas geralmente são relacionadas à ansiedade e ao medo da dor, e implicam na manutenção da incapacidade em indivíduos com dor crônica (VOWLES; GROSS, 2003). Se, em situaçóes simples, as dores podem surgir, o que devem pensar em relaçáo ao retorno ao trabalho? Quando se fala em dor crônica lombar, se deve considerar que existem aspectos psíquicos e sociais envolvidos. Em estudo de Vianne et al. (2003), tanto o bem-estar físico quanto o bem-estar mental tiveram relaçôes com a dor severa.

\section{3 "Ter que" fazer}

Os sujeitos acabam muitas vezes por fazer o que consideram que tem que ser feito (tarefas domésticas), mesmo sabendo que correrão o risco de sentir as dores, aspectos que interferem nos sintomas clínicos.

[...] vocêe dona de casa, você tem uma janta para fazer, você precisa arrumar um guarda-roupa, você tem roupa para passar, e você com dor, você faz! Muitas vezes eu tinha que fazer... não tinha ninguém para fazer! (42 anos, auxiliar de serviços gerais, gênero feminino).

[...] o que en tiver que fazer en faço... é muito dificil depender dos outros... muito dificil... depois eu fico arriada (53 anos, auxiliar de serviços gerais, gênero feminino).

[...] não vou mentir para você, eu faço... e é só fazer umas coisinhas a mais que pronto, já começa a doer sem parar (55 anos, pedreiro, gênero masculino).

Não se deve julgar o fato de fazer ou náo algo que possa ser prejudicial, sem antes investigar os contextos em que os sujeitos estáo inseridos, aspectos que necessitaria de maiores investigaçóes. Não se pretende aqui também culpabilizá-los e sim tentar compreender as situaçôes. Muitas vezes, não há ninguém que faça as tarefas e há sofrimento de não ser capaz de fazê-las sem desencadear as dores, se tornando um conflito interno. Parece haver uma tentativa de fuga frente a sensaçốes de fracasso e inutilidade, e o fazer poderia aliviar essas sensações e talvez a angústia, cabendo reflexôes sobre qual seria a pior dor.

Ter talvez uma consciência sobre os riscos para o surgimento das dores crônicas em atividades cotidianas parece não ser suficiente para evitá-los. Quando os sintomas cessam ou diminuem, os sujeitos tendem a realizar as tarefas.

[...] como é que uma dona de casa vai evitar? É dificil, é viver convivendo com essa dor. Melhora um pouquinho, e vocêjá faz. Mas você sabe que ela vai voltar (43 anos, auxiliar de serviços gerais, gênero feminino).

Ao realizar as tarefas, os sintomas podem ressurgir, e com riscos de se agravarem, especialmente se cuidados posturais não forem realizados e não se evitarem os esforços físicos. A invisibilidade dos sintomas e da doença também promove dúvidas sobre a dor que se sente e sobre a incapacidade (NEVES; NUNES, 2009; ALENCAR; OTA, 2011).

\section{4 $\mathrm{O}$ instrumental}

Foi aplicado o Instrumento Oswestry Low Back Pain Disability Questionnaire - OSW (FAIRBANK; PYNSENT, 2000) junto aos sujeitos entrevistados. Este questionário consiste em dez itens que se referem aos aspectos funcionais e estáo relacionados ao quanto o problema de dor lombar tem afetado o dia a dia. A Tabela 2 demonstra os escores obtidos e interpretaçóes.

Tabela 2. Escores e interpretações pelo Instrumento.

\begin{tabular}{ccl}
\hline $\begin{array}{c}\text { Sujeitos } \\
(\mathrm{n}=10)\end{array}$ & Escores & \multicolumn{1}{c}{ Resultado } \\
\hline E1* & $58 \%$ & Severa incapacidade \\
E2 & $44 \%$ & Severa incapacidade \\
E3 & $58 \%$ & Severa incapacidade \\
E4 & $34 \%$ & Moderada incapacidade \\
E5 & $58 \%$ & Severa incapacidade \\
E6 & $58 \%$ & Severa incapacidade \\
E7 & $50 \%$ & Severa incapacidade \\
E8 & $40 \%$ & Moderada incapacidade \\
E9 & $30 \%$ & Moderada incapacidade \\
E10 & $38 \%$ & Moderada incapacidade \\
\hline
\end{tabular}

*E1= entrevistado 1 , etc. 
Conforme demonstrado na Tabela 2, a maioria dos sujeitos $(n=6)$ apresentou severa incapacidade, com a doença afetando diversos aspectos do dia a dia, entre os quais se apontam os mais comuns: ao carregar pesos, no sentar-se, no ficar em pé e em atividades domésticas. Muitas dessas restriçóes se devem ao fato de a dor ser crônica e os sintomas se agravarem, em geral, conforme as atividades cotidianas são realizadas. A dor crônica provoca limitaçôes que vão além do aspecto físico, pois também abrange aspectos psicológicos e sociais que interferem nas atividades do cotidiano, o que impede uma satisfação pessoal, provocando situaçóes de esgotamento (POLIZELLI; LEITE, 2010). A vivência de uma doença crônica (em especial, de começo tardio) envolve um complexo processo de adaptaçáo e traz consigo um conjunto de alteraçóes que podem desafiar a visão que o indivíduo tem de si, das suas capacidades e do mundo (BISHOP, 2005). Os sujeitos do estudo passaram por vivências de incapacidade decorrentes da doença e sofrimento relacionado, além de possível desengano quanto a uma possibilidade de melhora. Junto às vivências, ocorreram mudanças de papéis sociais, representaçôes sociais, conflitos internos e relacionais, que podem ter contribuído para uma identidade de doente e de incapacitado, desencadeando severas e moderadas incapacidades observadas pelo instrumental, aspectos estes que necessitariam de maiores investigaçóes. Ainda, o "ter que" fazer algumas tarefas domésticas, na luta por manter talvez um sentimento de "utilidade", socialmente reconhecido, e um suposto bem-estar mental, pode ter agravado os casos clínicos. $\mathrm{O}$ indivíduo, por causa das dores crônicas, tem, em geral, sua rotina modificada e seu desempenho ocupacional comprometido. Em estudo de Alencar e Terada (2012), a dor crônica afetou atividades de lazer, sociais, causando, em alguns sujeitos, um desânimo "total" para a realização de atividades anteriormente prazerosas.

\section{Conclusão}

$\mathrm{O}$ afastamento por adoecimento relacionado ao trabalho pode trazer incapacidades e sofrimento. A funcionalidade humana é relacional e, portanto, complexa. Em geral, há necessidade de um processo de aceitação e superação das novas situações junto aos sujeitos acometidos por doença crônica lombar e que estão em situação de afastamento do trabalho. Tal situação requer um determinado tempo para adaptação no processo de reabilitação, que deve ocorrer com equipes compostas por diversos profissionais e em trabalhos interdisciplinares, incluindo atividades grupais e expressivas. Cabe lembrar que a dor que se sente pode não ser somente uma dor física e os aspectos psicossociais precisam ser investigados e considerados junto aos sujeitos com dores crônicas lombares, nos processos de reabilitação.

As análises pelo instrumental demonstraram os níveis elevados de incapacidades relatadas e percebidas pelos sujeitos. Esses níveis elevados, muitas vezes, não são condizentes com resultados de avaliações clínicas e com enfoques biomédicos, gerando, frequentemente, desconfiança e a necessidade de luta constante para comprovar a doença e a necessidade de tratamentos. Soma-se o fato de esses tratamentos nem sempre serem facilmente acessíveis, o que pode gerar sofrimento.

\section{Limitações do Estudo}

Este estudo não teve o objetivo de analisar todos os aspectos funcionais, devido a complexidade do tema. $\mathrm{O}$ número de participantes da amostra foi considerado baixo e eles estavam relacionados a um único serviço de saúde. Os participantes deste estudo podem ter compreendido os casos mais graves e, por este motivo, apresentaram moderada e severa incapacidade, e concordaram em participar do estudo. Tais aspectos necessitariam de maiores investigaçôes. Contudo, alguns aspectos analisados e discutidos evidenciaram algumas relaçóes existentes junto ao tema e aos sujeitos. Sugerem-se aprofundamentos em pesquisas futuras e com análises qualitativas sobre o tema, visando avanços nos processos de investigação e reabilitação, e sem visar a tentativa de controle e generalização.

\section{Referências}

ABREU, A. T. J. B.; RIBEIRO, C. A. B. Prevalência de lombalgia em trabalhadores submetidos ao programa de reabilitação profissional do Instituto Nacional do Seguro Social (INSS), São Luís, MA. Acta Fisiátrica, São Paulo, v. 17, n. 4, p. 148-153, 2010.

ALENCAR, M. C. B.; OTA, N. H. O afastamento do trabalho por LER/DORT: repercussōes na saúde mental. Revista de Terapia Ocupacional da Universidade de São Paulo, São Paulo, v. 22, n. 1, p. 60-67, 2011.

ALENCAR, M. C. B.; TERADA, T. M. O afastamento do trabalho por afecçốes lombares: repercussóes no cotidiano de vida dos sujeitos. Revista de Terapia Ocupacional da Universidade de São Paulo, São Paulo, v. 23, n. 1, p. 44-51, 2012.

BARDIN, L. Categorização. In: BARDIN, L. Análise de conteúdo. Lisboa: Ediçôes 70, 2011. p. 145-161. 
BATTISTELLA, L. R.; BRITO, C. M. M. Tendência e reflexóes: Classificação Internacional de Funcionalidade (CIF). Acta Fisiátrica, São Paulo, v. 9, n. 2, p. 98-101, 2002.

BISHOP, M. Quality of life and psychosocial adaptation to chronic illness and acquired disability: a conceptual and theoretical synthesis. Rehabilitation Counseling Bulletin, Washington, v. 48, n. 4, p. 219-231, 2005. http:// dx.doi.org/10.1177/00343552050480040301.

CANGUILHEM, C. O normal e o patológico. Rio de Janeiro: Forense, 2014. p. 189-190.

FAIRBANK, J. C.; PYNSENT, P. B. The oswestry disability index. Spine, New York, v. 25, n. 22, p. 29402952, 2000. PMid:11074683.

FARIAS, N.; BUCHALLA, C. N. A Classificação Internacional de Funcionalidade, Incapacidade e Saúde da Organização Mundial da Saúde: conceitos, usos e perspectivas. Revista Brasileira de Epidemiologia, São Paulo, v. 8, n. 2, p. 187-193, 2005. http://dx.doi.org/10.1590/ S1415-790X2005000200011.

FRITZ, M. et al. A randomized clinical trial of the effectiveness of mechanical traction for sub-groups of patients with low back pain: study methods and rationale. BMC Musculoskeletal Disorders, London, v. 81, n. 11, p. 1-10, 2010. PMid:20433733.

GAEDKE, M. A.; KRUG, S. B. F. Quem sou eu? A identidade de trabalhadores portadores de LER/DORT. Texto \& Contexto - Enfermagem, Florianópolis, v. 7, n. 1, p. 120-137, 2008.

GARCIA, J. B. S.; TORRES NETO, E. Atividade laboral em pacientes atendidos em um sérico ambulatorial de dor crônica. Revista Dor, São Paulo, v. 12, n. 3, p. 215-220, 2011.

GOLOB, A. L.; WIPF, J. E. Low back pain. The Medical clinics of North America, Philadelphia, v. 98, n. 3, p. 405468, 2014. PMid:24758954.

HAGEN, K. B.; TAMBS, K.; BJERKEDAL, T. A. A prospective cohort study of risk factors for disability retirement because of back pain in general working population. Spine, New York, v. 27, n. 16, p. 1790-1796, 2002. PMid:12195073.

HEDEAGER MOMSEN, A. M. et al. Multiple somatic symptoms in employees participating in a randomized controlled trial associated with sickness absence due to non-specific low back pain. Spine, Hagerstown, v. 14, n. 4, p. 373-378, 2014.

HELFENSTEIN, J. M.; GOLDENFUM, M. A.; SIENA, C. Occupational low back pain. Revista da Associação Médica Brasileira, São Paulo, v. 56, n. 5, p. 583-589, 2010. PMid:21152833.

HOY, D. et al. A systematic review of the global prevalence of low back pain. Arthritis Rheum, Atlanta, v. 64, n. 6, p. 2028-2037, 2012. PMid:22231424. http://dx.doi. org/10.1002/art.34347.
LANCMAN, S. O mundo do trabalho e a psicodinâmica do trabalho. In: LANCMAN, S.; SZNELWAR, L. I (Org.). Cristophe Dejours: da psicopatologia à psicodinâmica do trabalho. Rio de Janeiro: Fiocruz, 2008. p. 25-36.

MENDES, A. M.; CRUZ, M. R. Trabalho e saúde no contexto organizacional: algumas vicissitudes teóricas. In: TAMAYO, A. (Org.). Cultura e saúde nas organizaçôes. Porto Alegre: Artmed, 2004. p. 39-55.

NEVES, R. F.; NUNES, M. O. Incapacidade cotidiano e subjetividade: a narrativa de trabalhadores com LER/ DORT. Interface - Comunicação, Saúde, Educação, Botucatu, v. 13, n. 30, p. 55-66, 2009.

ORGANIZAÇÃO MUNDIAL DA SAÚDE - OMS. Organizaçấo Panamericana de Saúde - OPAS. CIF: Classificação de Funcionalidade, Incapacidade e Saúde. São Paulo: EDUSP, 2003.

PATARO, S. M.; FERNANDES, R. C. Trabalho físico pesado e dor lombar: a realidade na limpeza urbana. Revista Brasileira de Epidemiologia, São Paulo, v. 17, n. 1, p. 17-30, 2014. http://dx.doi.org/10.1590/1415$-790 X 201400010003$ ENG.

POLIZELLI, K. M.; LEITE, S. N. Quem sente é a gente, mas é preciso relevar: a lombalgia na vida das trabalhadoras do setor têxtil de Blumenau - Santa Catarina. Saúde e Sociedade, São Paulo, v. 19, n. 2, p. 405-417, 2010. http://dx.doi.org/10.1590/S010412902010000200016.

RAMOS, M. Z.; TITTONI, J.; NARDI, H. C. A experiência de afastamento do trabalho por adoecimento vivenciada como processo de ruptura ou continuidade nos modos de viver. Cadernos de Psicologia Social do Trabalho, São Paulo, v. 11, n. 2, p. 209-221, 2008. http://dx.doi. org/10.11606/issn.1981-0490.v11i2p209-221.

RIBEIRO, M. Core-sets da Classificaçâo Internacional de Funcionalidade, Incapacidade e Saúde. Revista Brasileira de Enfermagem, Brasília, v. 64, n. 5, p. 938-946, 2011. http://dx.doi.org/10.1590/S003471672011000500021.

ROCHA, P. R.; LIMA, M. A. Trabalhador doente e sua família: dinâmica, convivência e processo de retorno ao trabalho. Revista Baiana de Saúde Pública, Bahia, v. 35, n. 1, p. 143-158, 2011.

SALATE, A. C. B.; SUEISHI, A. M. Comparação da efetividade entre tratamento fisioterapêutico com terapia manual e eletroterapia na dor e incapacidade em indivíduos com lombalgia. Revista Terapia Manual, São Paulo, v. 9, n. 45, p. 584-589, 2011.

SALVETTI, M. D. Incapacidade em pessoas com dor lombar crônica: prevalência e fatores preditores. 2010. 122 f. Tese (Doutorado em Ciências) - Universidade de São Paulo, São Paulo, 2010.

SAMPAIO, R. F. et al. Aplicaçắo da Classificaçấo Internacional de Funcionalidade, Incapacidade e Saúde (CIF) 
na prática clínica do fisioterapeuta. Revista Brasileira de Fisioterapia, São Paulo, v. 9, n. 2, p. 129-136, 2005.

SAMPAIO, R. F.; LUZ, M. T. Funcionalidade e incapacidade humana: explorando o escopo da classificação internacional da Organização Mundial da Saúde. Cadernos de Saúde Pública, Rio de Janeiro, v. 25, n. 3, p. 475-483, 2009.

STAAL, J. B. et al. Occupational health guidelines for the management of low back pain: an international comparison. Occupational and Environmental Medicine, London, v. 60, n. 9, p. 618-626, 2003. PMid:12937181. http://dx.doi.org/10.1136/oem.60.9.618.

TOLDRÁ, R. C. et al. Facilitadores e barreiras para o retorno ao trabalho: a experiência de trabalhadores atendidos em um Centro de Referência em Saúde do Trabalhador-SP, Brasil. Revista Brasileira de Saúde Ocupacional, São Paulo, v. 35, n. 121, p. 10-22, 2010. http://dx.doi. org/10.1590/S0303-76572010000100003.
VIANNE, I. et al. Acceptance of pain is an independent predictor of mental well-being in patients with chronic pain: empirical evidence and reappraisal. Pain, Amsterdam, v. 106, n. 1-2, p. 65-72, 2003. PMid:14581112. http://dx.doi.org/10.1016/S0304-3959(03)00291-4.

VOWLES, K. E.; GROSS, R. T. Work-related beliefs about injury and physical capability for work in individuals with chronic pain. Pain, Amsterdam, v. 101, n. 3, p. 291-298, 2003. PMid:12583872. http://dx.doi. org/10.1016/S0304-3959(02)00337-8.

WEINER, D. K. et al. The relationship between pain, neuropsychological performance, and physical function in community-dwelling older adults with chronic low back pain. Pain Med, Malden, v. 7, n. 1, p. 60-70, 2006. PMid:16533199. http://dx.doi.org/10.1111/j.15264637.2006.00091.x.

ZAVARIZE, S. F. et al. Dor lombar crônica: implicaçóes do perfil criativo como estratégia de enfrentamento. Journal of Management \& Primary Health Care, Pernambuco, v. 5, n. 2, p. 188-194, 2014.

\section{Contribuição dos Autores}

Maria do Carmo e Janaina trabalharam na concepção, revisão e redação do artigo. Janaina participou do trabalho de campo. Maria do Carmo realizou o trabalho de orientação e supervisão do campo e estudo. Todos os autores aprovaram a versão final do texto.

\section{Fonte de Financiamento}

Fundação de Amparo à pesquisa do Estado de São Paulo - FAPESP e Coordenação de Aperfeiçoamento de Pessoal de Nível Superior - CAPES. 